\title{
Fenomenologia dos direitos humanos de Emmanuel Levinas
}

\author{
Phenomenology of human rights by Emmanuel Levinas
}

\section{Silvestre Grzibowski*}

Universidade Federal de Santa Maria (UFSM), Santa Maria, RS, Brasil

\section{Resumo}

Pretende-se no presente artigo, apresentar a fenomenologia dos direitos humanos de Emmanuel Levinas. Para isso, primeiramente verificar-se-á como os direitos humanos foram atrelados pelo saber científico e as consequências deixadas para a civilização, e ainda averiguar-se-á os direitos dos cidadãos sendo abarcados pelo pensamento filosófico a partir do eu racional que culminará no universal. Diante disso, Levinas está convencido que seria necessário fazer uma nova reflexão sobre os direitos humanos, não nos esquemas tradicionais e já conhecidos, porém repensá-los a partir dos direitos dos outros homens. A tese que este ensaio procurará sustentar é que a fenomenologia dos direitos humanos deve ser constituída a partir da fenomenologia da sensibilidade e da vida de cada indivíduo, e essa sensibilidade primordial e fundamental o fará sair do gozo na medida em que outro o desperta e o convoca para responsabilizar-se e cuidá-lo.

Palavras-chave: Emmanuel Levinas. Fenomenologia. Ética e direitos humanos.

\footnotetext{
* SG: Doutor em Filosofia, e-mail: silboski@yahoo.com.br
} 


\section{Abstract}

This article aims to present the phenomenology of human rights by Emmanuel Levinas. For this purpose, firstly we are going to check out how human rights were linked by scientific knowledge and the consequences left to civilization, and even ascertain the rights of the citizens being covered by philosophical thought from the rational self (individual) that will culminate in the universal. Considering this, Levinas is convinced that it would be necessary to make a new reflection on human rights, not in traditional schemes that are already known, but rethinking them from the rights of other men. The thesis that this essay will seek to sustain is that the phenomenology of human rights must be constituted from the phenomenology of sensitivity and from the life of each individual, and this primordial and fundamental sensitivity will make him leave the enjoyment in so far as another awakes him and convokes him to be responsible and takes care of him.

Keywords: Emmanuel Levinas. Phenomenology. ethics and human rights.

\section{Introdução}

Inicialmente é preciso expor que a obra de Levinas faz duras críticas ao absolutismo da racionalidade ocidental. A razão instrumental que se apresentava como si mesma, como única razão elaborando uma teoria generalizante, se esgotou no seu intento totalizador. Ou seja, ela se há exaurida ou fechada em si mesma e diante desta totalização não tem existido ou mais precisamente não abriu espaço para outras razões. Levinas averigua que o conhecimento objetivo é extremamente impetuoso, visto que não é capaz de entrar em contato com a realidade nem com a individualidade, mas somente alcança a generalidade. E somente o que está submetido à razão é filosofia. Isso gera, produz violência filosófica, moral e religiosa sem limites. Levinas segue o esquema deste pensamento sistematicamente e profetiza dizendo que o combate ou a luta é uma emanação deste modo de pensar que é a característica da cultura ocidental. Antes de ser uma violência física, ela é ideológica, de pensamento, no sentido de anular a individualidade de cada sujeito. Porque a violência consiste em reusar a singularidade de 
um ser alcançando-o como elemento do próprio cálculo e como caso particular de conceito. Assim sendo, a filosofia não fala da vida dos indivíduos, mas de conceitos. E ainda, considera o conhecimento objetivo ao abordar o ser, para apoderar-se dele, apoderar-se do outro, não oferecendo espaço para a alteridade. Por conseguinte, a relação será de dominação de um sobre o outro, especificamente quando um sujeito converge à individualidade do outro em um objeto, e o outro passa a ser não mais um indivíduo livre, e sim, um tema-objeto compondo uma imagem em uma representação.

Diante disso, o pensamento filosófico levinasiano busca edificar a partir da filosofia ética, um pensamento sobre os direitos humanos. Esse pensamento surge no meio de um deserto filosófico que levou a humanidade a praticar inúmeras barbáries, pois o homem não respeitou o Outro como pessoa, mas objetivou-o e reduziu-o a um artifício de conhecimento, a um tema, a um saber. Assim, os problemas dos direitos humanos aumentam drasticamente no mundo todo. Destaco aqui um dos problemas, talvez, um dos mais graves na atualidade: a questão da violência que tem gerado mais violência e a vida que vem sendo ameaçada em todas as suas dimensões. Levinas está convencido que é necessário (re)fazer uma nova reflexão sobre os direitos humanos, não nos esquemas conhecidos, porém repensá-los, não a partir dos "meus" direitos, mas dos outros, direitos dos outros homens. Ao arquitetar a proposição dos direitos humanos a partir da alteridade, constata que a filosofia ocidental se contrapõe com a noção básica dos direitos humanos porque ela sempre pensou a partir do mesmo, de um sujeito autônomo. Assim, ele aponta e responsabiliza a técnica (ciência) e a filosofia pelo esquecimento dos direitos fundamentais de cada ser humano, pois ambas marcam o avanço da civilização.

\section{Os Direitos Humanos e a Ciência}

A ciência, com todas as suas possibilidades de desenvolvimento, elabora técnicas cada vez mais sofisticadas e promete assegurar em suas realizações o respeito aos direitos humanos. Desse modo, os 
direitos são atrelados e assim permanecem nesse modo de pensá-los e constituí-los.

O desenvolvimento da técnica graças à extensão do saber através da qual a humanidade europeia se encaminhava a sua modernidade, é provavelmente, por si mesmo a modalidade baixo o qual o pensamento dos direitos humanos, colocado no centro da consciência de um mesmo, se amplia em sua concepção e se inscreve ou se exige como base de toda legislação humana que, ao menos se pensa como os direitos do homem em sua integridade, indispensável ou esperada" (LEVINAS, 1997, p. 134).

A fundamentação e a sustentação dos direitos são providas pelo saber teórico que está vinculado à técnica. Esse foi o legado herdado sobre os direitos dos cidadãos no ocidente. Mais precisamente, tornou-se uma disciplina técnica e racional que nasceu na Europa e estendeu-se por toda a humanidade. E ainda segue sendo europeia, porque além de resguardar toda a tradição, tonifica a academia e dita normas para a sociedade em geral. Por isso que ao estudarmos sobre os direitos, partimos do apriori que não é a vida do indivíduo, mas de um saber que é estreitamente técnico e que deve ser compreendido como tal.

O saber técnico-científico não somente promete aos cidadãos uma vida mais sofisticada e confortável, mas de fato proporciona-lhes concretamente. E no momento em que lhes é oferecido tal conforto, sobrepõe seus comportamentos e confere as exigências de ação ao ser humano que deve adequar-se aos seus princípios. Evidentemente, isso constituirá um determinismo onde o homem acabará sendo cada vez mais escravo da máquina e do sistema, principalmente porque a liberdade individual é extraída. "Em uma sociedade, inteiramente industrializada ou em uma sociedade totalitária - que precisamente resulta das técnicas sociais que se pretendem aperfeiçoar os direitos dos homens se encontram comprometidos pelas mesmas práticas, cuja motivação tem subministrado eles mesmos. Mecanização e servidão!" (LEVINAS, 1997, p. 136). O humanismo da humanidade acaba sendo instrumentalizado pela máquina. $\mathrm{O}$ homem passa a agir e a comportar-se como tal, respondendo aos comandos mecanicamente. As relações 
subjetivas e intersubjetivas são comprometidas porque o homem vive artificialmente e age como tal. E assim se constitui o homem-máquina. As ações não são mais espontâneas, mas instrumentalizadas. Desse modo, o sujeito não serve ao outro, mas torna-se servo da máquina para manter o sistema funcionando.

Outro ponto precisa ser mencionado, o uso da técnica na indústria bélica. Essas indústrias se utilizam dos avanços científicos para construírem armamentos potentes e eficazes para destruir o inimigo, mas na verdade os mais frágeis são atingidos e sofrem todas as consequências. A humanidade assiste os mais violentos genocídios e barbáries na atualidade que são praticados contra os mais fracos e assim identidades inteiras são extirpadas e vidas destruídas. Como afirma o pensador contemporâneo Michel Henry, ingressamos na barbárie. Exatamente, vivemos em um período de barbaridades, porém não é a primeira vez que a "humanidade mergulha na noite. Pode-se mesmo pensar que essa aventura amarga lhe ocorreu muitas vezes e é com a garganta apertada que o historiador ou arqueólogo levanta os vestígios de uma civilização desaparecida" (LEVINAS, 2012, p. 21). Este período de barbárie que a humanidade atravessa é, segundo ele, provocado pela ciência. Ela que elimina a vida e as culturas. A pergunta que um ser humano deverá fazer para si e para sua comunidade é exatamente essa: como cuidar de uma criança que foi ferida na guerra? Qual é a resposta ética que devemos ter para com o outro? Como falar de direitos do Outro homem? Por isso, Levinas protesta contra a técnica e a ciência que não têm respostas éticas para cuidar de uma pessoa ferida. Não falamos somente da ferida física, corporal, mas também da carne subjetiva, onde toda a individualidade da pessoa foi extremamente mexida.

\section{Os Direitos Humanos e a Filosofia}

O ulterior problema verificado por Levinas é filosófico, de modo especial como a filosofia, sobretudo a kantiana, apresenta a liberdade de cada indivíduo. Kant prioriza a liberdade de cada pessoa e esquece o outro. Essa proposição intrigava demasiadamente o pensamento 
de Levinas, especificamente, o esquecimento do outro para constituir o dever moral autonomamente. "O que Kant chama de 'reino dos fins' é uma pluralidade de vontades livres, unida pela razão" (LEVINAS, 1997, p. 137). Existem liberdades individuais e elas são múltiplas, assim se instaura o conflito. Perante essa presunção, Levinas demonstra que o conflito nasce nas vontades livres de cada sujeito. E somente cumpre seu dever quem está animado por uma boa vontade e uma boa intenção, sem medir o que vai suceder, fazendo abstração de qualquer outra consideração, cumprindo assim, o dever moral. A boa vontade é guiada pela razão.

A razão nos foi dada como razão prática, isto é, como faculdade que deve exercer influência sobre a vontade, então o seu verdadeiro destino deverá ser produzir uma vontade, não só boa quiçá como meio para outra intenção, mas uma vontade boa em si mesma, para o que a razão era absolutamente necessária, uma vez que a natureza de resto agiu em tudo com acerto na repartição das suas faculdades e talentos (KANT, 2009, p. 25-25. Grifos do autor).

Para Kant, qualquer um pode estabelecer que o critério da moralidade resida ou não, na pureza da intenção. “Qualquer que seja a circunstância, é moral unicamente quem atua com a pura intenção de cumprir seu dever, sem ceder às suas inclinações, por respeito exclusivo do dever de agir corretamente" (CHALIER, 2002, p. 38). Aqui, é importante frisar que, para Kant, a razão ordena seus preceitos sem cair nas inclinações. Consiste em agir sem deixar-se levar pelos apegos e por outras inclinações como as afetivas. Por isso, se o indivíduo se compromete em dizer sempre a verdade, em nenhuma circunstância poderá mentir, mesmo que seja para salvar uma vida. A voz dura do dever deverá sempre falar mais alto do que qualquer outro clamor, sobretudo, falar mais alto do que os brados dos mais frágeis para que não possam ser ouvidos os gemidos, como os dos torturados, que às vezes, mentem para salvar-se, ou livrar-se o mais rápido possível da tortura corporal e psíquica.

A filosofia que arquiteta o princípio absoluto da moralidade e o respeito à moralidade e a humanidade, não respeita a singularidade de cada pessoa. Ou seja, o comportamento moral deve sujeitar-se, 
segundo Kant, à ideia de humanidade como um fim em si mesmo (KANT, p. 73, 2009) e jamais ao outro, frágil, vulnerável como um fim em si, mas sempre priorizando o cumprimento do dever. "A vontade não será boa se não se cumprir a condição de respeitar absolutamente" (CHALIER, 2002, p. 41). Para Kant, o sujeito de boa vontade atua por puro respeito ao dever, mesmo que ele seja um ser antipático com os demais, a meta final sempre será o dever e o cumprimento dele. Pois, a ideia de humanidade e universalidade conduz o seu comportamento. “O sujeito moral pode atuar com simpatia, mas não por simpatia a boa vontade não pressupõe amizade alguma pelo homem, ainda tampouco o exclui, atua pelo dever" (CHALIER, 2002, p. 44).

Na sociedade existem sujeitos racionais livres, que têm vontades e que ambicionam cumprir com os seus deveres. Levinas vê problemas nessa proposição porque são duas ou mais vontades que imperam ao mesmo tempo. Para Kant, os conflitos são selecionados quando se instaura a justiça. Um direito justo, conforme as leis universais. Todos devem adequar-se às leis e de tal modo estabelece-se a justiça. Assim, se impõe o rigor da justiça que não respeita as liberdades individuais. No momento em que as singularidades são ajustadas, formam-se as unicidades. Passamos a assistir o nascimento da dor, a dor do indivíduo, porque sofre, pois, a singularidade, a subjetividade do sujeito se sujeita, ou mais precisamente é sujeita à totalidade, quão reina o espírito objetivo como verdadeiro. Diante disso inúmeras questões surgirão: como estabelecer a justiça? Os princípios indispensáveis para as instituições, sobretudo, para a justiça são os que constituem a moralidade? E a crueldade que nasce na sociedade e que a boa vontade racional ignora integralmente? O que dizer dos desvios de responsabilidades para que os deveres sejam cumpridos? É justo massacrar as singularidades das pessoas em nome da universalidade da lei, mesmo que ela desrespeite a singularidade? Será possível a partir da teoria kantiana edificar a paz? A justiça de uma razão deverá se sobrepor à outra? Não será possível pensar a justiça a partir do Outro, do mais fraco, do vulnerável que sofre apesar da lei moral estar sendo cumprida?

O modo como Kant tratou de estabelecer a justiça é correto, porém, não deixa de ser uma certa limitação ao direito e à livre vontade. 
Então Levinas reflete: "Permanece ainda a questão de saber se a limitação do direito pela justiça não terá sido já uma maneira de tratar a pessoa como um objeto, submetendo a ela, a incomparável comparação ao pensamento - ao passar (passagem) pela famosa balança da justiça - e, assim, o cálculo" (LEVINAS, 1997, p. 137). De modo que a individualidade de cada um acaba sendo abarcada pelo eu autônomo ${ }^{1}$ que ao impor-se, estabelece as suas próprias leis e faz com que todos a respeitem. As leis universais são constituídas pelos sujeitos autônomos para serem seguidas. Por isso, na interpretação de Levinas, a vida da pessoa torna-se limitada pela justiça que está submetida à(s) lei(s). Sendo assim, a má paz é preferida à guerra, porém, esta má paz é abstrata porque foi construída pelos poderes do estado e a política é assegurada pela obediência à lei. Essa paz constituída pelos poderes é artificial, aparente porque os conflitos não foram solucionados. O estado, ou os chefes de estado se impõem sobre o indivíduo, neste caso a paz é aparente porque é estabelecida apenas por alguns membros ${ }^{2}$. A ordem racional se obtém ao preço das necessidades próprias do estado, porque ele é o representante e o responsável em elaborar e executar as leis com as quais os cidadãos deverão concordar. E a adesão não surge da espontaneidade, do respeito de um pelo outro, mas o indivíduo deverá adequar-se obrigatoriamente à lei. Aqui, Levinas detecta o nascimento do estado totalitário, porque se impõe e se reprime o homem e seus direitos com a promessa ou com a sensação de uma volta plena dos direitos humanos devolvidos. Existe uma promissão de uma vivência de paz, de justiça, no entanto, elas serão mascaradas, pois são firmemente vigiadas pelos defensores das leis impondo aos cidadãos restrições e punições.

Claro que o homem vive em uma sociedade e a partir das relações surge o estado com todas as suas instituições. Levinas está ciente disso, entretanto, terá inúmeras dificuldades em aceitá-lo pela lógica totalitária que estabelece a partir do Eu universal. Exatamente porque nessa lógica o outro não é mais ponderado como indivíduo, mas será

Sobre este tema desenvolvo no artigo: Levinas e Kant: um estudo a partir da autonomia e heteronomia (2010, pp. 545,556).

2 "A paz dos impérios saídos da guerra se funda na guerra. Não devolve aos seres alienados sua identidade perdida. Para isso é necessário uma relação original e originária com o ser" (LEVINAS, 2006, p. 48). 
arrazoado como gênero. "É a hora da Justiça, da comparação dos incomparáveis, 'juntando-se' em espécies e gênero humanos. É hora das instituições habilitadas julgarem, é a hora dos Estados em que as instituições se consolidam, é a hora da Lei Universal que é sempre a dura Lex, é a hora dos cidadãos se tornarem iguais perante à lei" (LEVINAS, 2004, p. 263). Embora Levinas reconheça que o estado se esforce para elaborar as leis que brotam da reciprocidade da comunidade e que tem como missão educar as pessoas para uma boa relação social, o analisa como o grande instituidor da violência. Associa o Estado à guerra porque dispõe de muitos aparatos, inclusive a força para manter a paz. “O estado, por sua vez, faz apelo ao aparato da força, força que obriga não pela razão/educação, nem com apelos à liberdade/responsabilidades individuais, mas pela força do poder e pelo poder da força" (PIVATTO, 2001, p. 223). Quando as tentativas de diálogos se esgotam, o estado intervém e recorre para uso de suas forças para reprimir as pessoas. Por isso, o nosso autor ao averiguar que a filosofia ocidental desrespeita e anula a alteridade, não mede palavras para acusá-la e nos induz a conferir que estamos em guerra constantemente, todos contra todos. "Como na guerra moderna, em toda a guerra, as armas se voltam contra quem às detém. Nada fica de fora. A guerra não mostra a exterioridade nem o outro entanto que outro; destrói a identidade do mesmo" (LEVINAS, 2006, p. 48). Protesta contra esta filosofia que tem levado a humanidade a viver na insegurança, porque há submetido à alteridade no mesmo, violentando o outro. Ainda se poderia dizer que tem privilegiado a liberdade individual sem responsabilidade. E os resultados, se é que podemos dizer assim, são milhões e milhões de vidas que foram (e ainda continuam sendo) exterminadas em diversas guerras que foram produzidas e que vêm assombrando gerações e povos inteiros, desafiando cada vez mais a humanidade no sentido de sobrevivência. Porque o medo da violência do outro vem abismando cada vez mais. A impressão que se tem é que o outro sempre é nosso inimigo.

A filosofia ocidental é o império do ser onde o mesmo se submete à violência, a toda diferença e a toda alteridade até cair em um círculo neutro cujos componentes terminam todos no mesmo plano, sem hierarquia. Esta mesmice só pode manter-se exercendo uma violência 
contra todo aquele que altere a ordem e encontre uma violência sem limites que não se detém nem ante os horrores de Auschwiztz.

\section{Fenomenologia dos Direitos Humanos}

Para contrapor as teorias, Levinas inicialmente recusa o estado totalitário e abomina a guerra, para propor a fenomenologia dos direitos humanos que origina a vida sensível do sujeito e da responsabilidade de um para com o outro.

Os direitos fundamentais de cada indivíduo são constituídos pela vida sensível de cada um. Desse modo, o pensador objeta as teorias que elaboram os direitos a partir de leis, que são necessárias, porém, insuficientes. As leis da vida antecedem as leis racionais. Para Levinas, os direitos de cada homem são princípios latentes e cada um tem o direito de viver dignamente. Essa é a lei primeira e essencial. Independentemente de qualquer luta ou esforço dentro da vida social as pessoas têm seus direitos, que não são méritos conquistados pois os direitos à vida são a apriori. "Anteriores a toda concessão: a toda tradição, a toda jurisprudência, a toda distribuição de privilégios, de dignidade ou de títulos, a toda consagração de uma vontade que pretenderia ser tomada por razão" (LEVINAS, 1997, p. 131-132). A vida constitui os direitos de cada indivíduo e a sociedade se constitui no respeito de cada individualidade e não ao contrário. Aqui, encontramos uma proximidade muito grande como o pensamento de Michel Henry que diz: “a vida é fenomenológica num sentido original e fundador. A subjetividade fenomenológica é criadora da fenomenalidade. A fenomenalidade surge originalmente ao mesmo tempo em que a vida, sob a forma de vida e de nenhuma outra maneira. "E por subjetividade nós entendemos isto, o que prova o soi-même" (HENRY, 2003, p. 26). A vida "se sente, se experimenta em si mesma" (s'éprouve soi-même) (2004, p. 31). Henry sustenta que o sujeito e somente ele mesmo pode discorrer sobre ela (vida), afinal o indivíduo, a vivencia e a experimenta et nic et nunc "aqui e agora". Evidentemente, a fenomenologia dos direitos humanos que parte da vida, procura apresentar que a vida é mais simples do que a imaginamos, visto que todos 
a vivemos e surpreendentemente não precisamos de teorias para vivê-la, prova disso que nenhuma pessoa a experimenta a partir de um saber teórico, apenas a vivencia. Por isso, cada um sabe o que ela é, ela mesma fala o que sente ao ser experimentada (s'éprouve soi-même). Por isso, Levinas contrariamente ao discurso totalitário da racionalidade ocidental sustenta o argumento da unicidade. Pertencemos ao gênero humano, no entanto, somos únicos. No entanto, a unidade do eu penso não é o que faz a humanidade do eu, onde na reflexão busca refugiar-se sobre si mesmo, repousar, permanecer na consciência de si. Para Levinas o eu é movimento, ou melhor, saída de si mesmo, de sua comodidade, e se constrói na resposta ao apelo do outro. $\mathrm{O}$ eu sem identidade, eleito pelo outro para responder as misérias. Por isso para Levinas o eu, o humano, é um para o outro, para a responsabilidade.

No segundo aspecto a fenomenologia da sensibilidade ganha outro terreno, agora não mais no sentido concreto, muito próximo do dia-a-dia do gozo, a proximidade do próximo comanda a análise de outra face da sensibilidade, ou seja, na exposição do Eu "Moi" ao Outro "Autrui", que se apresenta como vulnerabilidade. Assim sendo, desenvolve-se a tese de que a sensibilidade somente pode ser sensibilidade quando é vulnerabilidade ou exposição total ao outro. Essa exposição, ou mais precisamente a subjetividade do "moi" chega ao extremo. Sofrer pelo outro. Abertura, exposição total ao outro, até a expiação, assumindo as culpas do outro, responsabilizando-se plenamente por este outro desnudo, miserável que me olha. "Onde o outro me regarde; não para perceber-me, mas afetando-me, importando-me com alguém a quem devo responder" (LEVINAS, 1997, P. 139). Caracteriza esta sensibilidade não no modo de intencionalidade, o ato de perceber não é intencional como havia proposto Husserl, mas é não intencionalidade, passividade, em Levinas será co-mandamento, ou seja, o sujeito é tomado pelo outro, afetado e é feito refém. A exposição em tanto que sensibilidade é muito mais passiva, é a inversão do conatus de essendi ${ }^{3}$. Seria a vulnerabilidade própria. Sem de-

3 « Un avoir-été-offert-sans-retenue, ne trouvant pas de protection dans une quelque consistance ou identité d'état. Avoir-été-offert-sans-retenue où l'infinitif passé souligne le non-présent, le non-commencement, la non-initiative de la sensibilité -non-initiative qui plus ancienne que tout présent, est non pas une passivité contemporaine et contrepartie d'un acte, mais l'en deçà du libre et du non-libre qu'est l'anarchie du bien ». (LEVINAS, 1974, p. 94). 
fesa. "A passividade da ofensa, a 'hemorragia' do para-o-outro, é arrancar da boca o pão que a boca saboreia em pleno gozo" (LEVINAS, 1974, p. 93). No dizer de Levinas, anterior ao ponto zero significa ausência de proteção e de cobertura. Não existe intervenção inteligível.

A subjetividade, efeito de seu ser afetado pelo Outro, é receptividade, suscetibilidade e vulnerabilidade. Isso a determina como sensibilidade e lhe confere um sentido moral. A sensibilidade significa o mesmo que ser-para-o-outro e é a constituição do sujeito da responsabilidade. Responder ao outro é dar-se e dar, o que somente pode tornar-se efetivo através da sensibilidade e a corporeidade. Segundo Levinas, um-para-o-outro quer dizer um que deve dar ao outro e, portanto, um que tem mãos para dar. Assim, a sensibilidade tanto proximidade, tanto significação, tanto um-para-outro, significa dar. Mas este dar não pode ser um dar sobrado, dar por dar, dar porque sobra. Há que ser um oferecer como o pão tirado da boca que degusto. "Significação que, por conseguinte, significa alimentar, vestir, alojar nas relações materiais onde a matéria se mostra somente na sua materialidade" (LEVINAS, 1974, p. 97). Aqui, encontramos concretamente o que Levinas chama de relação ética. Ou seja, sem corpo não há doação: um espírito puro não pode fazer-se a cargo do próximo. Levinas considera tão decisiva a relação de dar com a corporeidade, que determina o sujeito da responsabilidade como corpo. "a subjetividade humana é de carne e osso" (LEVINAS, 1993, 217). Exatamente por isso, chama de sujeito encarnado, de carne e osso, não um fenômeno. A relação não resulta de contato a partir da consciência intencional. Porque a subjetividade é sensibilidade, exposição aos outros. Aqui se faz necessário evidenciar a importância da fenomenologia da corporeidade para a constituição dos direitos humanos, porque mostra que o outro é de carne e osso, que tem fome, que come e que clama por justiça, não teórica, mas ética. Sensibilidade, contato como um oferecer-se pelo outro. A relação é de proximidade, fraternidade entre seres que respiram.

Se o sujeito é tomado pelo outro numa relação de proximidade e de fraternidade, nos perguntamos: como podemos discorrer sobre a liberdade do sujeito? Para Levinas a liberdade se dá na fraternidade na qual se afirma a responsabilidade de um para o outro e que "no concreto, os direitos humanos manifestam a consciência como direito do 
outro e do que devo responder" (LEVINAS, 1997, p. 140. Grifo do autor). Precisamente, na vivência concreta e no dia-a-dia, é aí justamente onde os direitos humanos se manifestam através do respeito, do cuida$\mathrm{do}^{4}$ com o outro que é diferente de mim. O nosso autor deixa bem claro, que os direitos e as leis não devem jamais ser teóricos, porque eles se manifestam, são zelados nas relações humanas. "Manifestar-se originalmente como direitos de outro homem e como dever para um eu, como os meus direitos na fraternidade, eis aqui a fenomenologia dos direitos humanos" (LEVINAS, 1997, p. 140). Fenomenologicamente toda a humanidade é na sua origem responsável por cuidar do outro. A fenomenologia dos direitos humanos passa pelo cuidado da vida, essa é a nossa responsabilidade primeira e última.

Não existe na filosofia levinasiana um sujeito instituído, onde antes de tudo recebe a ordem para num segundo momento agir e responsabilizar-se. Levinas coliga a própria responsabilidade com sujeito, não faz a distinção entre ambos. Aqui, novamente, Levinas se diferencia do kantismo, pois, a moral levinasiana dirá que somos responsáveis pelos outros antes de escolhermos, o que não equivale ser o dono dos seus próprios atos. Responsabilidade, que não tenho assumido em nenhum momento, em nenhum presente. Sendo assim, o nosso autor não apenas discursa sobre o mandato ou empenho não assumidos, mas também de responsabilidade e vassalagem não assumidas. A responsabilidade, ou obediência prévia à decisão e ao exercício de qualquer atividade.

\section{Considerações finais}

A fenomenologia dos direitos humanos de Levinas consiste primeiramente em sair da cegueira do naturalismo e reconhecer que detrás de cada homem encontra-se um ser humano que tem seus direitos fundamentais, para isso, é necessário transcender todos os ismos.

40 pensador Hans Jonas em suas teses desenvolve também a tese sobre o cuidado da vida. JONAS, Hans 0 Princípio Responsabilidade: Ensaio de uma Ética para a civilização tecnológica. RJ: Contraponto / PUC-RI0, 200. 
Respeitar as pessoas humanas como elas são, como elas vivem as suas vidas, com todas as suas diferenças, na sua unicidade e irredutibilidade. Cada pessoa vivendo o que ela é, sendo irredutível, jamais poderá ser reduzida ou ser englobada em rótulos. A violência somente será atenuada na medida em que as diferenças forem respeitadas por todos os indivíduos.

Nesse sentido, os direitos humanos não pertencem e não poderão ser construídos pelos países "civilizados", mas os direitos humanos deverão ser respeitados em todos os países, em todos os continentes. Onde a vida está sendo ameaçada pela enfermidade, pela fome, pela violência, é aí que ela deverá ser vigiada. E ao cuidarmos dela, tomamos cuidado com os direitos humanos. Este zelo, deveria ser a primeira e a única lei a ser seguida.

Por fim, dizer não à padronização de leis e de valores, mas partir de uma relação respeitosa com o outro. Relação desprovida da vontade racional de dominar o outro e muito menos de fazer uma lei jurídica para que seja aplicada, como diz Levinas: "é em nome da responsabilidade por outrem, da misericórdia, da bondade às quais apela o rosto do outro homem, que todo o discurso da justiça se põe em movimento, sejam quais forem às limitações e os rigores da dura Lex que ele terá trazido à infinita benevolência para com outrem" (LEVINAS, 2004, p. 263). Não podemos pensar a moralidade a partir da universalidade, mas ir ao encontro da singularidade, da inquietude moral, da vida das singularidades e das vidas que sofrem violências e atentados.

\section{Referências}

CHALIER, C. Por una moral más allá del saber. Kant y Levinas. Traducción a la edición española de Jesús María Ayuso Díez. Madrid: Caparrós, 2002.

GRZIBOWSKI, S. Levinas e Kant: um estudo a partir da autonomia e heteronomia. Aurora, Curitiba, v. 22, n. 31, p. 545-556, jul./dez, 2010.

HANS, J. O Princípio Responsabilidade: Ensaio de uma Ética para a civilização tecnológica. RJ: Contraponto / PUC-RIO, 2006. 
KANT, I. Fundamentação da metafísica dos costumes. Tradução de Paulo Quintela. Lisboa: Edições 70/LDA, 2009.

HENRY, M. Phénoménologie de la vie tome II De la subjectivité. Paris: Puf, 2003.

HENRY, M. Phénoménologie de la vie tome IV Sur l'éthique et la religion. Paris: Puf, 2004.

LEVINAS, E. Autrement qu'être ou au-delà de l'essence. Den Haag : M. Nijhooff, 1974.

LEVINAS, E. Difficile liberté: essais sur le Judaïsme. Paris : Albert Michel, 1976.

LEVINAS, E. De Dieu que vient à l'Idée. Paris : Librairie Philosophique J. Vrin, 1982.

LEVINAS, E. Alterité et transcendance. Montpellier: Fata Morgana, 1995.

LEVINAS, E. Fuera del sujeto. Traducción a la edición española de Roberto Ranz Torrejón y Cristina Jarillot Rodal. Madrid: Caparrós, 1997.

LEVINAS, E. Entre nós: ensaios sobre a alteridade. Tradução de Pergentino Pivatto (Coord.). Petrópolis: Vozes, 2004.

LEVINAS, E. Totalidad e infinito. Ensayo sobre la exterioridad. Traducción e introducción a edición española de Daniel E. Guillot. Salamanca: Sígueme, 2006. PIVATTO, P. S. Responsabilidade e Justiça em Levinas. Véritas, Porto Alegre, v. 46, n. 2, p. 217-230, jun. de 2003.

Recebido: 10/10/2015

Received: $10 / 10 / 2015$

Aprovado: $18 / 12 / 2015$

Approved: 12/18/2015 
